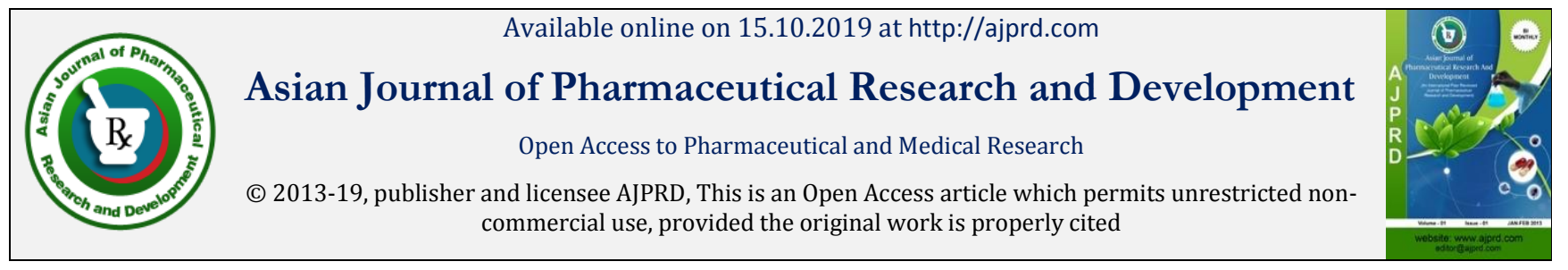

Open○ Access

Research Article

\title{
Formulation and Characterization of Cefixime Phytosomes for Oral Drug Delivery
}

\author{
Jain Saloni*, Ancheriya Rahul, Srivastva S, Soni Shankar lal, Sharma Mukesh
}

Department of Pharmaceutics, Arya College of Pharmacy, Kukas, Jaipur, Rajasthan, India

\begin{abstract}
A B S T R A C T
Novel drug delivery systems (NDDS) are one of the most strategies which enable to overcome the problems related to drug bioavailability. It is the rate and extent to which a drug becomes available to the target tissue after its administration. Over the last century, phyto-chemical science and phyto-pharmacological science established numerous plant compounds with various biological activities and health promoting benefits such as anti-mutagenicity, anti-carcinogenicity and anti-oxidative activity, for age-related diseases namely memory loss, osteoporosis, diabetic wounds, immune and liver disorders, etc. Herbal medicines have been known since eons for their safety, efficacy, folk acceptability and fewer side effects.
\end{abstract}

Key Word:- Anti-mutagenicity, osteoporosis, anti-carcinogenicity,

A R T I C L E I N F O: Received 08 June 2019; Review Completed 27 July 2019; Accepted 18 sept.2019; Available online 15 Oct. 2019
Cite this article as:
$\begin{aligned} & \text { Jain S, Ancheriya R, Srivastva S, Soni S, Sharma M, Formulation And Characterization of Cefixime } \\ & \text { Phytosomes For Oral Drug Delivery, Asian Journal of Pharmaceutical Research and Development. 2019; 7(5):65-73 } \\ & \text { *Address for Correspondence: }\end{aligned}$
$\begin{aligned} & \text { Saloni Jain, Department of Pharmaceutics, Arya College of Pharmacy, Kukas, Jaipur, Rajasthan, India }\end{aligned}$

\section{INTRODUCTION}

$\mathrm{S}$ ince ancient times the therapeutic uses of traditional medicines and phyto-medicines have proved very popular for health maintenance by various means. The advancement in the field of herbal drug delivery started recently with the aim to manage human diseases efficiently [3]. Every nation is seeking health care beyond the traditional boundaries of modern medicine; turning to self medication in the form of herbal remedies. Most of bioactive constituents of phyto-medicines are water soluble molecules (e.g. Phenolics, glycosides, flavonoids etc.). However, water soluble phytoconstituents are limited in their effectiveness because they are poorly absorbed when taken orally or when applied topically. Many approaches have been developed to improve the oral bioavailability, such as inclusion of solubility and bio availability enhancer, structural modification and entrapment with the lipophilic carriers and thus extensive research in the field of herbal drug delivery systems as a means of improving the therapeutic indices of drugs is inevitable. The use of formulation technology to deliver herbal products and drugs by improved absorption and, as a consequence, produce better results than those obtained

by conventional herbal extracts. Phytosome are not liposome; structurally the two are distinctly different. The phytosome is a unit of a few molecules bonded together, while liposome is an aggregate of many phospholipid molecules and encloses other phyto-active molecules but without specially bonding to them [4]. Phytosome technology is a breakthrough model for marked enhancement of bioavailability, significantly greater clinical benefit, assured delivery to the tissues, without compromising nutrient safety [5].

Therapeutic benefits of novel drug delivery systems

- Increase efficacy of the drug.

- Site specific delivery.

- Decrease toxicity/side effects.

- Viable treatments for previously incurable diseases.

- Potential for prophylactic applications.

- Lower health care costs both short and long term.

- Better patient compliance

METHODOLOGY:-

\section{Experimental Work}

\section{Preparations of cefixime-phospholipid Complex} Phytosome

The cefixime-phospholipid Complex was prepared by refluxing cefixime and phospholipid S100 in different millimolar ratios of $(1: 1,1: 2,1: 3,1: 41: 5,1: 6$ and 
1:7).Briefly, accurately weighed amounts of cefixime and phospholipid $\mathrm{S} 100$ were placed into a $100 \mathrm{~mL}$ round bottom flask and dissolved in $20 \mathrm{~mL}$ of methanol. The reaction temperature of the reflux was controlled at $60{ }^{\circ} \mathrm{C}$ using a water bath for $5 \mathrm{~h}$. The resultant clear solution was dried at $60^{\circ} \mathrm{C}$ under vacuum to remove traces of solvents in order to obtain the cefixime-phospholipid complex. The prepared thin layer had been kept overnight in room temperature prior to hydration. This dried film was hydrated with $10 \mathrm{ml}$ distilled water in a rotary at $60^{\circ} \mathrm{C}$. The phytosome was finally sonicated for 4 minutes in a probe sonicator, with $60 \%$ amplitude and 5 seconds on-off interval. All phytosome was stored in the refrigerator.

Table 1: Composition of different Phytosome formulations containing millimolar ratio of cefixime and phosphatidylcholine S100 (PC).

\begin{tabular}{|l|l|l|l|}
\hline S. No. & Formulation Code & $\begin{array}{l}\text { Drug Ratio: Phosphatidylcholine } \\
\text { S100 Ratio(milimolar) }\end{array}$ & Methanol (ml) \\
\hline 1 & F1 & $1: 1$ & 20 \\
\hline 2 & F2 & $1: 2$ & 20 \\
\hline 3 & F3 & $1: 3$ & 20 \\
\hline 4 & F4 & $1: 4$ & 20 \\
\hline 5 & F5 & $1: 5$ & 20 \\
\hline 6 & F6 & $1: 6$ & 20 \\
\hline 7 & F7 & $1: 7$ & 20 \\
\hline
\end{tabular}

\section{Evaluation of Phytosome}

Visual Appearance: Phytosome can range from translucent to milky, depending on the composition and particle size.

\section{Optical microscopy}

Optical Microscopy of drug loaded phytosome formulation was determined by optical microscopy at 100x magnification.

\section{Particle size and zeta potential determinations}

Vesicle properties, particle size diameter and zeta potential, were determined at room temperature by Zeta Potential/ Particle Sizer analyzer. Phytosome formulations

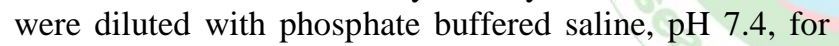
Zeta potential and particle size determination, respectively].

\section{Solubility Study of drug Phospholipid complex}

Solubility determination of Pure cefixime and cefiximephospholipids complex was carried out by adding excess of cefixime or phospholipids complex to $2 \mathrm{ml}$ of water or $\mathrm{n}$-octanol in sealed glass containers at $25^{\circ} \mathrm{C}$. The liquids were agitated for $24 \mathrm{~h}$, and then centrifuged to remove excessive cefixime (15 min, 15,000 rpm). The supernatant was collected \& the concentration of cefixime was determined spectrophotometrically.

\section{Drug Content}

Drug Content of phytosome loaded can be determined by dissolving accurately weighed $100 \mathrm{mg}$ of phytosome loaded in $10 \mathrm{ml}$ methanol. After appropriate dilution absorbance may be determined by UVSpectrophotometer $(\kappa \max =288 \mathrm{~nm})$. The drug content was calculated.

\section{Determination of Entrapment efficiency}

The entrapment efficiency of phytosome was determined by calculating the amount of entrapped cefixime in the phytosomes. To determine the entrapment efficiency of cefixime in phytosome, an appropriate amount of dispersion was transferred in culture tube. The dispersion was centrifuge for $15 \mathrm{~min}$ at $15000 \mathrm{rpm}$. After centrifugation the supernatant was collected and Percentage Drug Entrapment amount of free cefixime was determined spectrophotometrically $(\Lambda \max =288 \mathrm{~nm})$. The entrapment efficiency has been determined according to the following equation:

$\mathrm{EE} \%=\frac{\mathrm{W}_{\text {(Added drug) }}-\mathrm{W}_{\text {(free drug) }}}{\mathrm{W}_{\text {(Added drug) }}} \times 100$

Where, W (added drug) is the amount of drug added during the preparation of phytosomes, $\mathrm{W}$ (free drug) is the amount of free drug measured in the lower chamber of the culture tube after centrifugation.

\section{In-Vitro Drug Release Study}

In vitro release kinetics of phytosome was determined in this work using dialysis method. In brief, phytosome $(10 \mathrm{~mL})$ or drug solution with the equivalent drug concentration was enclosed in a dialysis bag and then placed in $100 \mathrm{~mL}$ of phosphate buffer saline (PBS) pH 6.8 used as release media. The entire system was kept at $37^{\circ} \mathrm{C} \pm 0.5^{\circ} \mathrm{C}$ with continuous magnetic stirring. At selected time intervals $(0.25,0.5,1,1.5,2,3,4,5,6,8,10,12$ and 24 hour), $3 \mathrm{~mL}$ of solution was withdrawn from the release medium and replenished with the same volume of release medium. The collected samples were suitably diluted and analyzed by UV-visible spectrophotometer at 288nm. [24]

\section{RESULTS AND DISCUSSIONS}

\section{Result of Preformulation study of drug}

Table 2: Organoleptic Properties of Cefixime

\begin{tabular}{|l|l|l|}
\hline Sr. no. & Properties & Inferences \\
\hline 1. & Colour & White to light yellow \\
\hline 2. & Odour & Odourless \\
\hline 3. & Form & Crystalline \\
\hline 4. & Taste & Bitter \\
\hline
\end{tabular}


Table 3: Melting Point of Cefixime

\begin{tabular}{|l|l|l|}
\hline Drug & Reference M.P. & Observed M.P. \\
\hline Cefixime & $218-225^{\circ} \mathrm{C}$ & $221.667 \pm 0.755^{\circ} \mathrm{C}$ \\
\hline
\end{tabular}

\section{UV Spectroscopy Determination of absorption maxima}

Absorption maxima of Cefixime were found to be at 288 $\mathrm{nm}$ similar to literature as shown in Figure 1

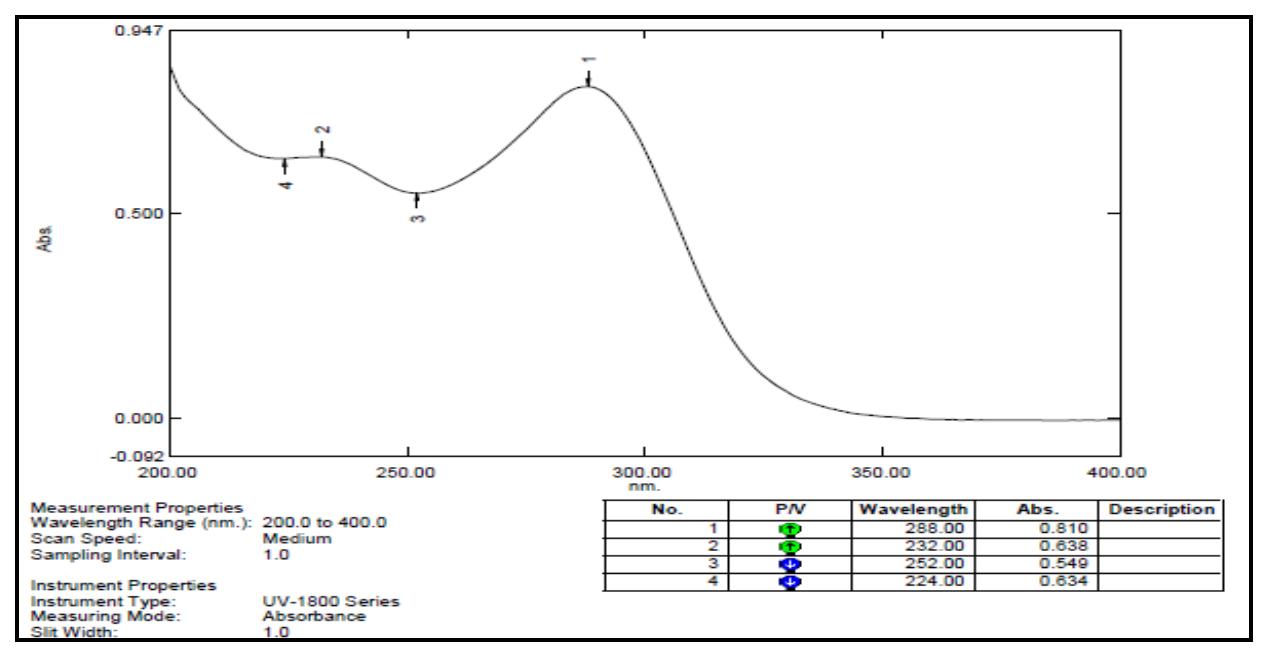

Figure 1: UV Spectrum of Cefixime

\section{Preparation of standard curve of Cefixime}

Table 4: Calibration curve of Cefixime $\left(\lambda_{\max }=288 \mathrm{~nm}\right)$

\begin{tabular}{|l|l|l|}
\hline Sr. No. & Concentration $\boldsymbol{\mu g} / \mathbf{m l}$ & Absorbance \\
\hline 1 & 2 & $0.102 \pm 0.002$ \\
\hline 2 & 4 & $0.197 \pm 0.001$ \\
\hline 3 & 6 & $0.290 \pm 0.002$ \\
\hline 4 & 8 & $0.373 \pm 0.002$ \\
\hline 5 & 10 & $0.474 \pm 0.001$ \\
\hline 6 & 12 & $0.573 \pm 0.004$ \\
\hline 7 & 14 & $0.650 \pm 0.001$ \\
\hline 8 & 16 & $0.741 \pm 0.001$ \\
\hline 9 & 18 & $0.811 \pm 0.001$ \\
\hline 10 & 20 & $0.892 \pm 0.001$ \\
\hline
\end{tabular}

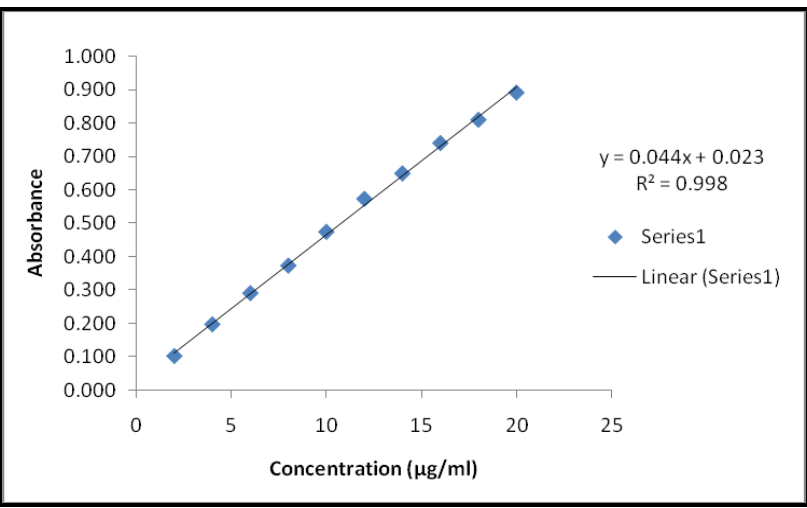

Figure 2: Graph of standard calibration curve of Cefixime

Table 5: Result of regression analysis of UV method for estimation of Cefixime

\begin{tabular}{|l|l|}
\hline Statistical parameters & Results \\
\hline$\lambda$ max & $288 \mathrm{~nm}$ \\
\hline Regression equation: $\mathrm{y}=\mathrm{mx}+\mathrm{C}$ & $\mathrm{Y}=0.044 \mathrm{x}+0.023$ \\
\hline Slope $(\mathrm{m})$ & 0.044 \\
\hline Intercept $(\mathrm{C})$ & 0.023 \\
\hline Correlation coefficient $\left(\mathrm{r}^{2}\right)$ & 0.998 \\
\hline
\end{tabular}

Table 6: Solubility studies of Cefixime for different solvents

\begin{tabular}{|l|l|l|}
\hline Sr. No & Solvent & $\begin{array}{l}\text { Solubility In }(\mathbf{M g} / \mathbf{M l}) \\
(\text { Mean } \pm \text { SD) } *\end{array}$ \\
\hline 1 & Methanol & $117.348 \pm 0.694$ \\
\hline 2 & Ethanol & $16.614 \pm 0.099$ \\
\hline 3 & PBS 7.4 & $13.682 \pm 0.039$ \\
\hline 4 & Acetone & $11.894 \pm 0.057$ \\
\hline 5 & PBS 6.8 & $5.826 \pm 0.047$ \\
\hline 6 & 1nhcl & $1.530 \pm 0.002$ \\
\hline 7 & Water & $1.414 \pm 0.007$ \\
\hline 8 & Chloroform & $0.021 \pm 0.0003$ \\
\hline 9 & DCM & $0.009 \pm 0.0003$ \\
\hline
\end{tabular}

* Each value is average of three independent determination

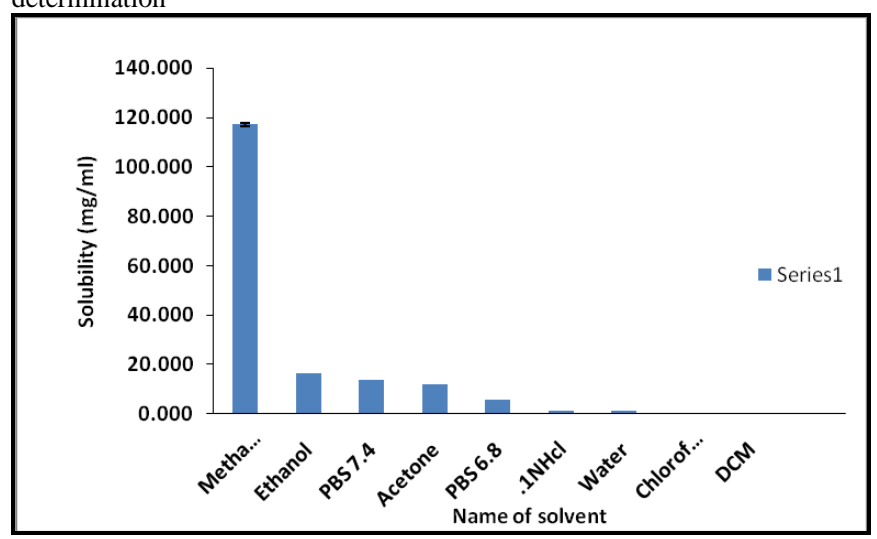

Figure 3: Solubility study of drug in different solvents

\section{Partition coefficient determination}

Table 7: Partition coefficient determination of Cefixime

\begin{tabular}{|l|l|c|}
\hline Partition coefficient of drug & Solvent system & Log P Values \\
\hline Cefixime & n- octanol:water & $-0.442 \pm 0.005$ \\
\hline
\end{tabular}

Discussion: The partition coefficient of Cefixime in nOctanol: Water was found to be $-0.442 \pm 0.005$ this indicates that the drug is Hydrophilic in nature. 


\section{FTIR of Cefixime and Excipients}
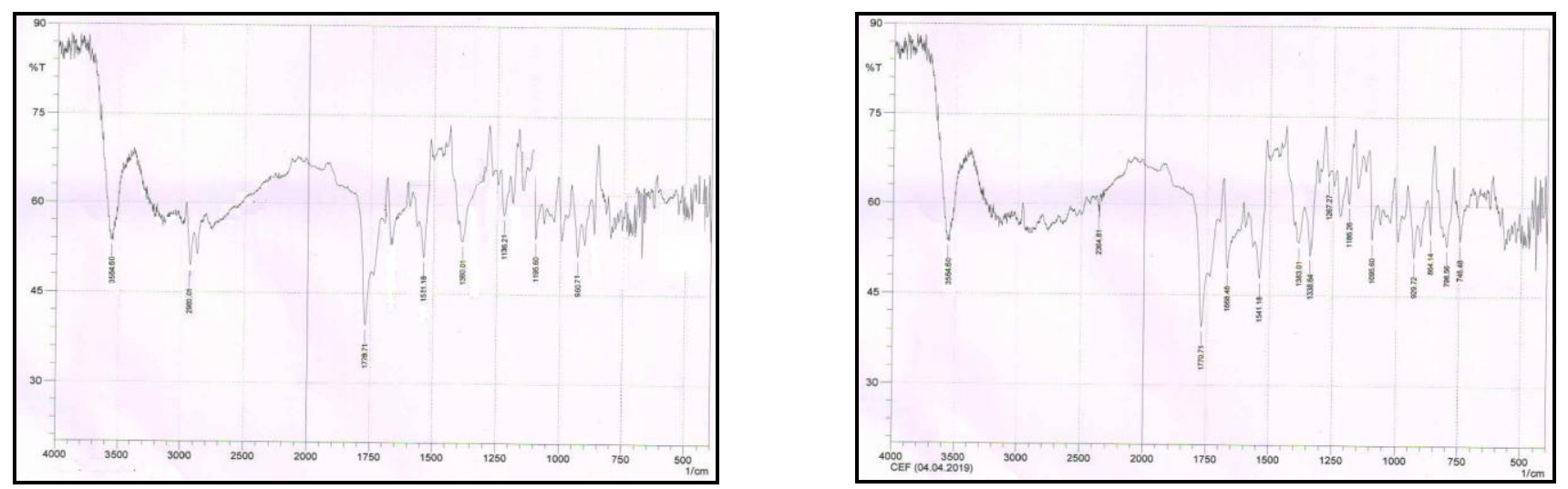

Figure 4: FTIR spectrum of Cefixime

Table 8: FTIR interpretation of Cefixime

\begin{tabular}{|l|l|l|}
\hline Characteristics Peaks & Reported $\left(\mathbf{c m}^{-1}\right)$ & Observed $\left(\mathbf{c m}^{-1}\right)$ \\
\hline C-H stretch & 2942.02 & 2364.81 \\
\hline OH, stretch, COOH & 3563.91 & 3564.60 \\
\hline C O stretch CONH & 1669.09 & 1668.48 \\
\hline C N stretching, aromatic & 1337.88 & 1338.64 \\
\hline C O, stretch, COOH & 1771.79 & 1770.71 \\
\hline C H,bending & 746.16 & 746.48 \\
\hline C C, stretch & 1542.09 & 1541.18 \\
\hline
\end{tabular}

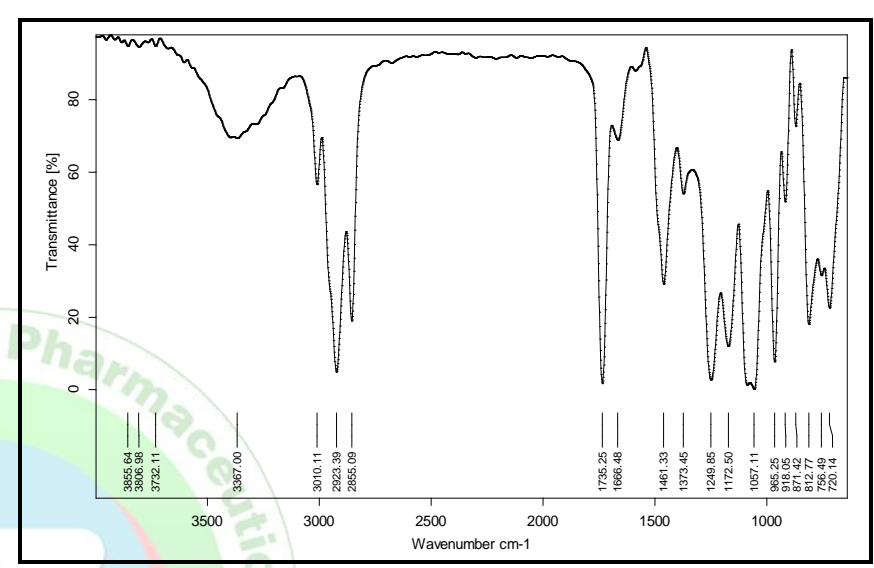

Figure 5: FTIR spectrum of Phosphatidylcholine S100

Table 9: FTIR interpretation of Phosphatidylcholine S100

\begin{tabular}{|l|l|l|}
\hline Characteristics Peaks & Reported $\left(\mathbf{c m}^{-\mathbf{1}}\right)$ & Observed $\left(\mathbf{c m}^{-\mathbf{1}}\right)$ \\
\hline C-H stretching band of long fatty acid chain & 2918.3 and 2854.96 & 2923.39 and 2856.09 \\
\hline Carbonyl stretching band in the fatty acid ester & 1728.22 & 1735.25 \\
\hline C $=$ O stretch $\alpha, \beta$ - unsaturated aldehydes, ketones & $1710-1665$ & 1666.48 \\
\hline P=O stretching band & 1236.37 & 1249.85 \\
\hline P-O-C stretching band & 1093.65 & 1057.11 \\
\hline N+(CH3)3 stretching & 966.34 & 985.25 \\
\hline
\end{tabular}

\section{FTIR of Pure drug and physical mixtures:}

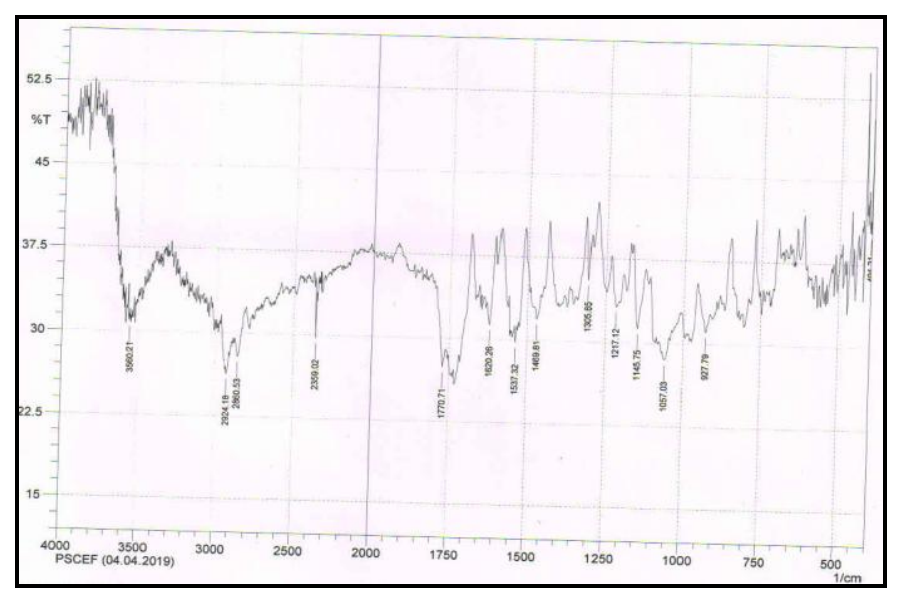

Figure 6: FTIR spectra of Cefixime and phosphatidylcholine S100 
Table 10: FTIR interpretation of Cefixime and phosphatidylcholine S100

\begin{tabular}{|l|l|l|}
\hline Characteristics Peaks & $\begin{array}{l}\text { Reported } \\
\left(\mathbf{c m}^{-1}\right)\end{array}$ & $\begin{array}{l}\text { Observed } \\
\left(\mathbf{c m}^{-1}\right)\end{array}$ \\
\hline C-H stretch & 2364.81 & 2359.02 \\
\hline OH, stretch, COOH & 3564.60 & 3560.21 \\
\hline C O stretch CONH & 1668.48 & 1620.26 \\
\hline C N stretching, aromatic & 1338.64 & 1305.85 \\
\hline C O, stretch, COOH & 1770.71 & 1770.71 \\
\hline C C, stretch & 1541.18 & 1537.32 \\
\hline $\begin{array}{l}\text { C-H stretching band of } \\
\text { long fatty acid chain }\end{array}$ & $\begin{array}{l}2923.39 \text { and } \\
2856.09\end{array}$ & $\begin{array}{l}2924.18 \text { and } \\
2860.53\end{array}$ \\
\hline P=O stretching band & 1249.85 & 1217.12 \\
\hline P-O-C stretching band & 1057.11 & 1057.03 \\
\hline N+(CH3)3 stretching & 985.25 & 927.79 \\
\hline
\end{tabular}

\section{Preparation of Cefixime -phospholipid Complex} Phytosome

The method of preparation of phytosome was found to be simple and reproducible.

\section{Evaluation of Phytosome}

\section{Appearance of Phytosome}

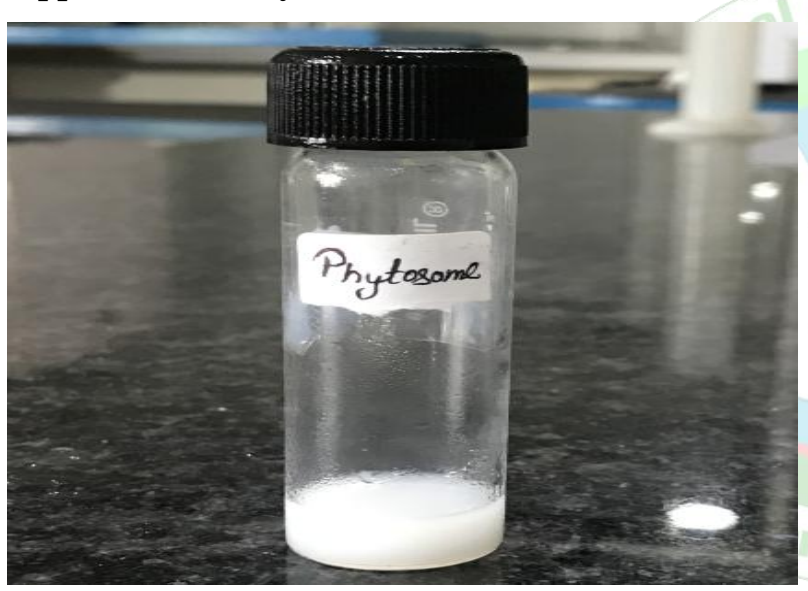

Figure 7: Cefixime-phospholipid Complex Phytosome.

Discussion: From the above Figure 7, we observe the milky white appearance.

\section{Optical microscopy}

Optical Microscopy of drug loaded phytosome formulation was determined by optical microscopy at 100x magnification and result was shown in Figure 8 [7]

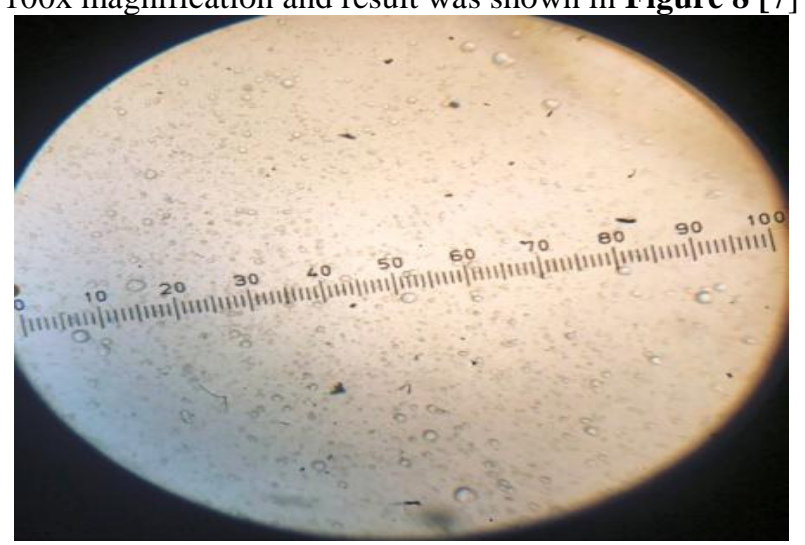

Figure 8: Optical Microscopy of Phytosome
Discussion: Uniform, regular and rigid vesicles were observed in optical microscopic view.

\section{Particle size and zeta potential determinations}

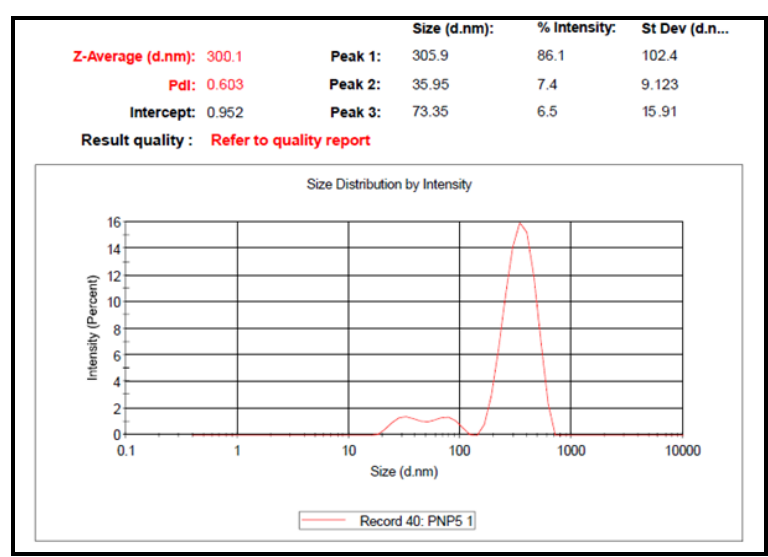

Figure 9: Particle size peak of phytosomal formulation

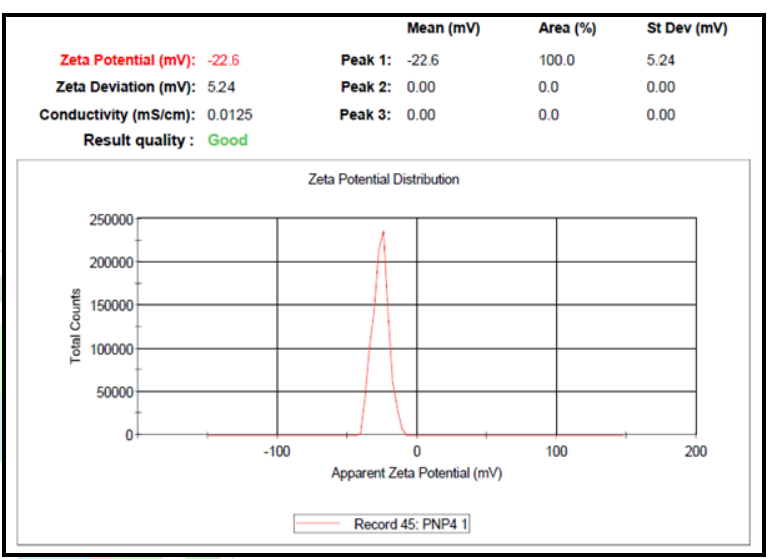

Figure 10: Zeta potential graph of phytosomal formulation

Table 11: n-Octanol Solubility of Pure drug \& Cefixime-phospholipid Complex.

\begin{tabular}{|l|l|}
\hline $\begin{array}{c}\text { Drug: Phospholipid Ratio } \\
\mathbf{m}(\mathbf{m m})\end{array}$ & Solubility in n-octanol $(\mathbf{m g} / \mathbf{m l})$ \\
\hline Pure drug & $0.593 \pm 0.010$ \\
\hline $1: 1$ Complex & $0.623 \pm 0.005$ \\
\hline $1: 2$ Complex & $0.756 \pm 0.011$ \\
\hline $1: 3$ Complex & $0.892 \pm 0.009$ \\
\hline $1: 4$ Complex & $1.033 \pm 0.003$ \\
\hline $1: 5$ Complex & $0.499 \pm 0.011$ \\
\hline $1: 6$ Complex & $0.386 \pm 0.010$ \\
\hline $1: 7$ Complex & $0.220 \pm 0.005$ \\
\hline
\end{tabular}

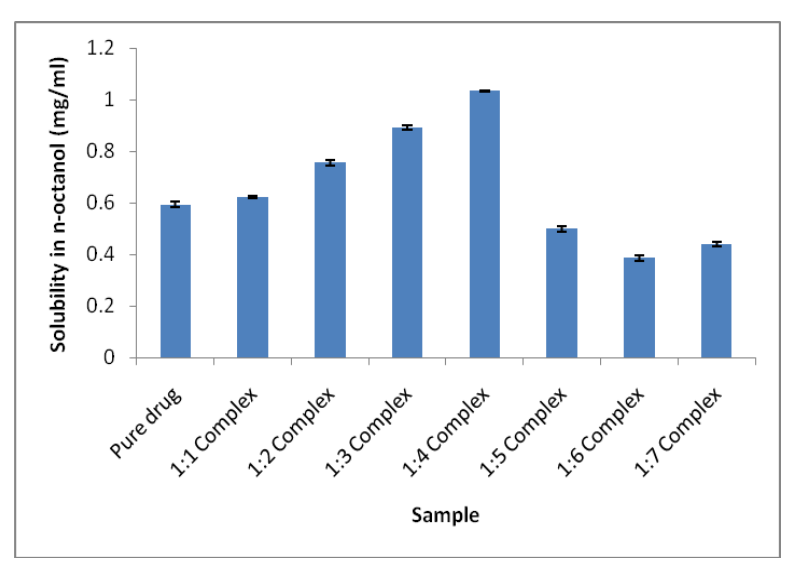

Figure 11: n-Octanol Solubility of Pure drug \& Cefixime phospholipid Complex 


\section{Percentage drug content}

Table 12: Percentage drug content of different Phytosome formulation containing Cefixime-phospholipid Complex.

\begin{tabular}{|l|l|l|}
\hline S. No. & Formulation Code & Percentage drug Content \\
\hline 1 & F1 & $97.273 \pm 0.455$ \\
\hline 2 & F2 & $88.181 \pm 0.909$ \\
\hline 3 & F3 & $94.106 \pm 0.932$ \\
\hline 4 & F4 & $89.848 \pm 0.694$ \\
\hline 5 & F5 & $91.515 \pm 0.525$ \\
\hline 6 & F6 & $94.879 \pm 0.735$ \\
\hline 7 & F7 & $92.197 \pm 0.347$ \\
\hline
\end{tabular}

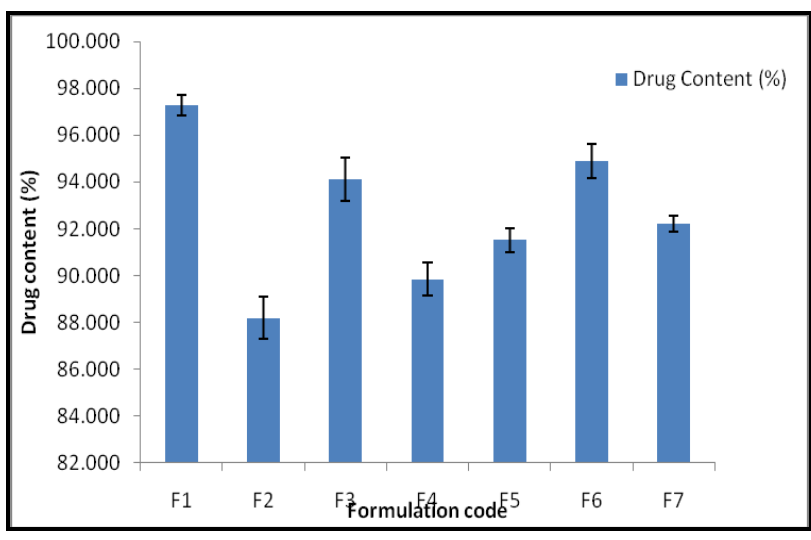

Figure 12: Percentage drug content of Phytosomal formulations containing Cefixime-phospholipid Complex

Discussion: The drug content of phytosome was found to be $88.848 \pm 0.694$ and $97.273 \pm 0.455 \%$, respectively. The percentage drug content of all formulations was found to be satisfactory. Hence, the method adopted for phytosome formulations was found to be suitable.

\section{Entrapment efficiency}

Table 13: Percentage Entrapment efficiency of different Phytosome formulation containing Cefixime-phospholipid Complex.

\begin{tabular}{|l|l|l|}
\hline S. No. & Formulation Code & $\begin{array}{l}\text { Entrapment efficiency } \\
(\%)\end{array}$ \\
\hline 1 & F1 & $77.591 \pm 0.045$ \\
\hline 2 & F2 & $79.894 \pm 0.160$ \\
\hline 3 & F3 & $83.864 \pm 0.079$ \\
\hline 4 & F4 & $88.909 \pm 0.091$ \\
\hline 5 & F5 & $73.970 \pm 0.069$ \\
\hline 6 & F6 & $72.727 \pm 0.164$ \\
\hline 7 & F7 & $69.803 \pm 0.095$ \\
\hline
\end{tabular}

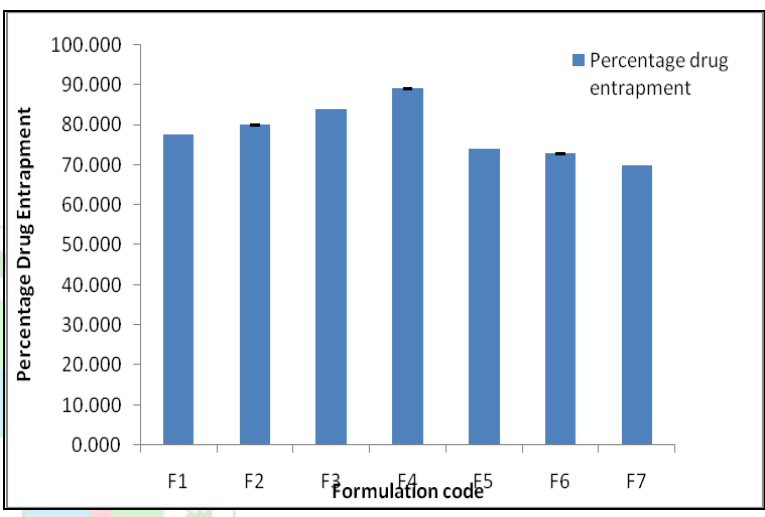

Figure 13: Percentage entrapment efficency of Phytosomal formulations containing Cefixime-phospholipid Complex

\section{FTIR spectral analysis}

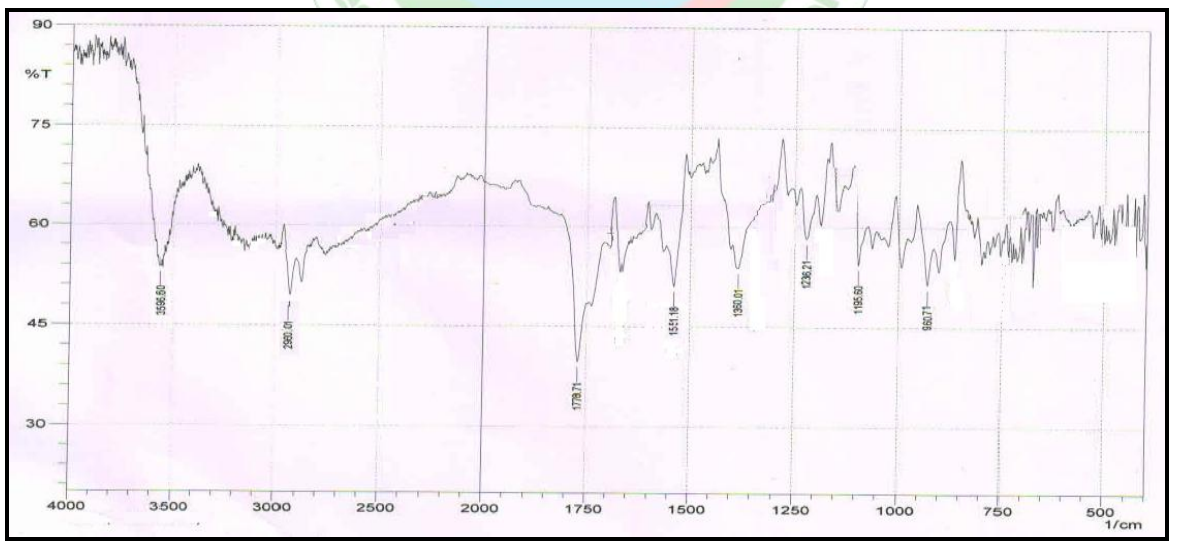

Figure 14: FTIR spectra of Formulation F4

Table 14: FTIR interpretation of FTIR spectra of Formulation F4

\begin{tabular}{|l|l|l|}
\hline Characteristics Peaks & Reported $\left(\mathbf{c m}^{-\mathbf{1}}\right)$ & Observed $\left(\mathbf{c m}^{-\mathbf{1}}\right)$ \\
\hline OH, stretch, COOH & 3564.60 & 3596.60 \\
\hline C N stretching, aromatic & 1338.64 & 1360.01 \\
\hline C O, stretch, COOH & 1770.71 & 1778.71 \\
\hline C C, stretch & 1541.18 & 1551.18 \\
\hline $\begin{array}{l}\text { C-H stretching band of long } \\
\text { fatty acid chain }\end{array}$ & 2923.39 and 2856.09 & 2960.01 \\
\hline $\begin{array}{l}\text { P=O stretching band } \\
\text { P-O-C stretching band }\end{array}$ & 1249.85 & 1236.21 \\
\hline N+(CH3)3 stretching & 985.25 & 1195.60 \\
\hline
\end{tabular}




\section{In-vitro Drug release study}

Table 15: Percentage drug release of Formulation F4 and Pure drug

\begin{tabular}{|l|l|l|}
\hline Time $(\mathbf{H r})$ & Drug Release of Pure drug(\%) & $\begin{array}{l}\text { Drug Release of F4 } \\
\text { Formulation }(\%)\end{array}$ \\
\hline 0.00 & 0.000 & 0.000 \\
\hline 0.25 & $18.121 \pm 0.100$ & $4.900 \pm 0.331$ \\
\hline 0.50 & $34.667 \pm 0.410$ & $14.155 \pm 0.146$ \\
\hline 1.00 & $56.727 \pm 0.090$ & $22.909 \pm 0.091$ \\
\hline 1.50 & $80.939 \pm 0.860$ & $29.091 \pm 0.182$ \\
\hline 2.00 & $99.394 \pm 0.520$ & $34.758 \pm 0.212$ \\
\hline 3.00 & - & $42.009 \pm 0.307$ \\
\hline 4.00 & - & $47.303 \pm 0.139$ \\
\hline 5.00 & - & $51.839 \pm 0.231$ \\
\hline 6.00 & - & $56.485 \pm 0.344$ \\
\hline 8.00 & - & $63.182 \pm 0.182$ \\
\hline 10.00 & - & $69.464 \pm 0.168$ \\
\hline 12.00 & - & $73.758 \pm 0.319$ \\
\hline 24.00 & - & $82.455 \pm 0.182$ \\
\hline
\end{tabular}

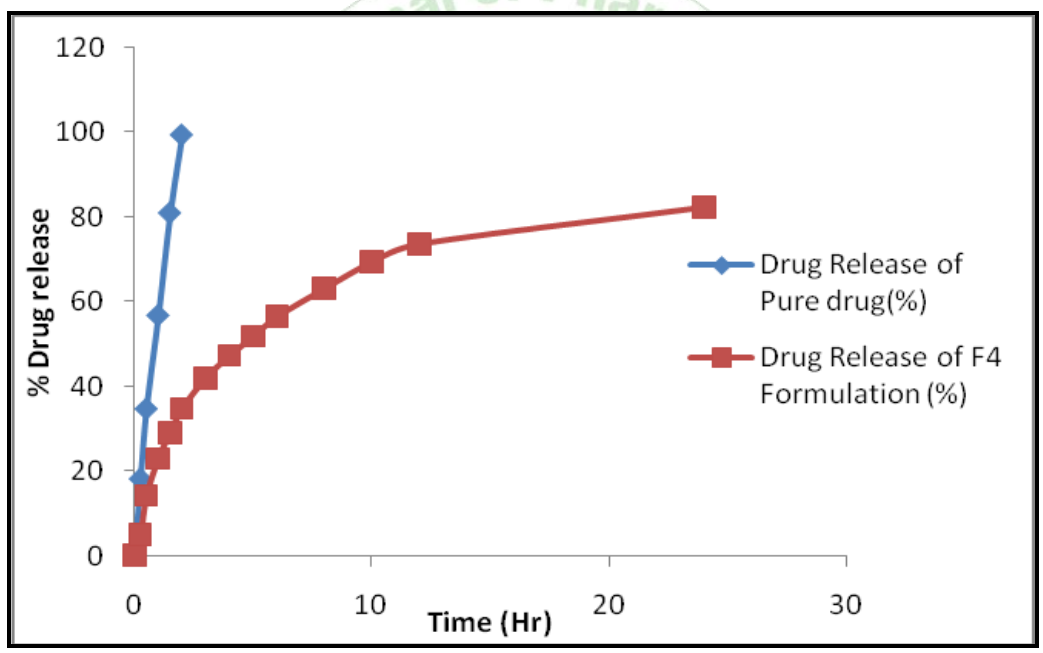

Figure 15: In-Vitro Drug release of F4 Formulation and pure drug

\section{In-vitro drug release kinetic}

In-vitro drug release kinetic study data of formulation F4 was given below.

\section{Zero order}

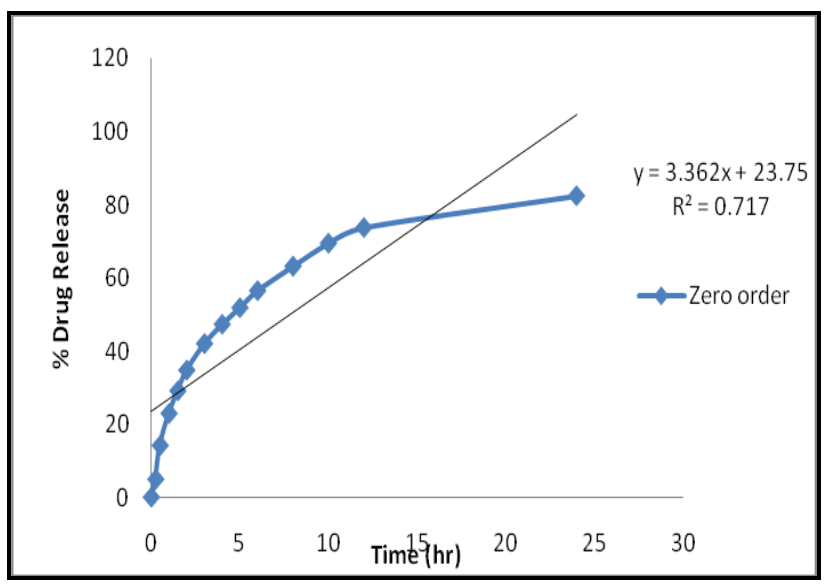

Figure 21: Zero order graph of formulation F4

\section{First Order}

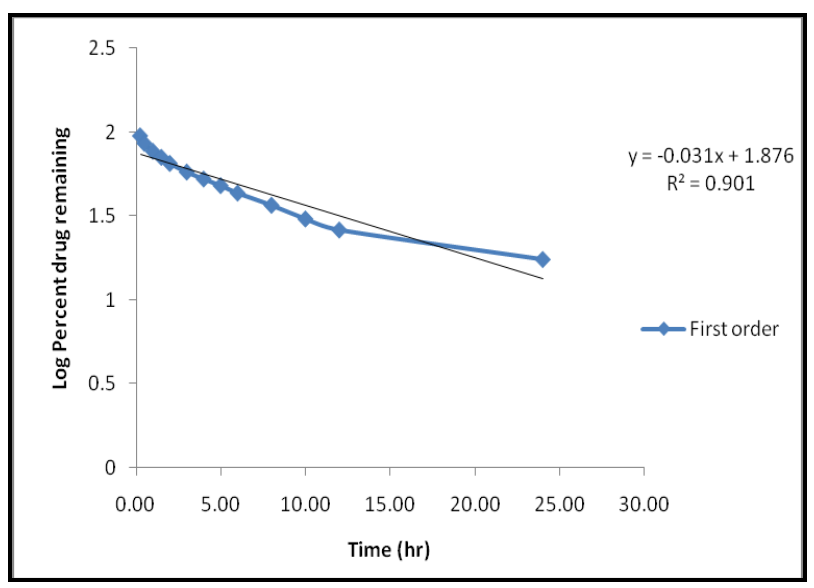

Figure 16: First order graph of formulation F4 


\section{Higuchi model}

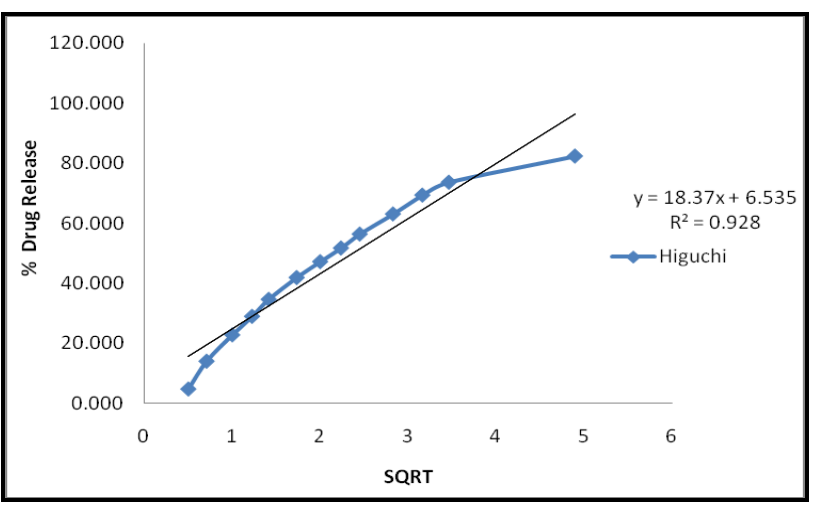

Figure 23: Higuchi order graph of formulation F4

\section{Korsmeyer peppas model}

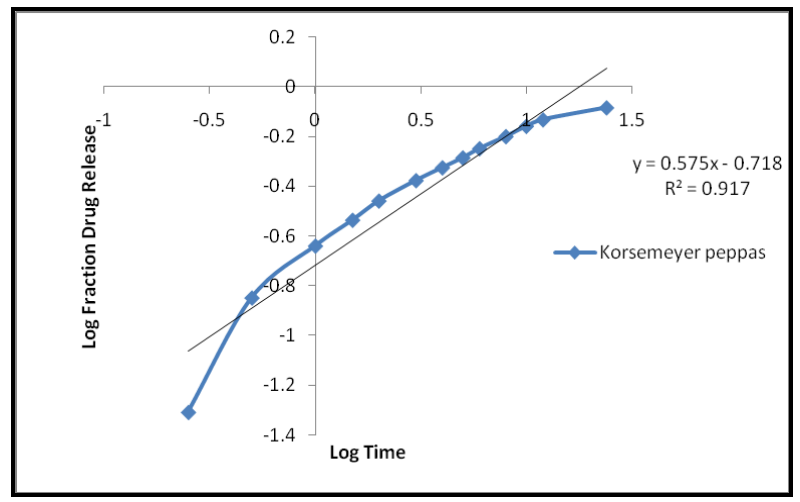

Figure 17: Korsmeyer peppas order graph of formulation F4

Table 16: Kinetic equation parameter of formulation F4

\begin{tabular}{|c|c|c|c|c|c|c|c|c|}
\hline \multirow{2}{*}{ Formulation } & \multicolumn{2}{|c|}{ Zero order } & \multicolumn{2}{|c|}{ First order } & \multicolumn{2}{|c|}{ Higuchi } & \multicolumn{2}{|c|}{ Korsmeyer-Peppas } \\
\hline & $\mathbf{R}^{2}$ & $\mathbf{K}_{\mathbf{0}}$ & $\mathbf{R}^{2}$ & $\mathbf{K}_{\mathbf{0}}$ & $\mathbf{R}^{2}$ & $\mathbf{K}_{\mathbf{0}}$ & $\mathbf{R}^{2}$ & $\mathbf{K}_{\mathbf{0}}$ \\
\hline F3 & 0.717 & 3.362 & 0.901 & -0.031 & 0.928 & 18.37 & 0.917 & 0.575 \\
\hline
\end{tabular}

\section{Summary and Conclusion:-}

The goal of any drug delivery system is to provide therapeutic amount of drug to the proper site in the body and also to achieve and maintain the desired plasma concentration of drug for a particular period of time. However, incomplete release of drug, shorter residence time of dosage form in the gastrointestional tract and high hepatic first pass effect leads to lower bioavailability. Such limitations of the conventional dosages forms have paved to an era of controlled and novel drug delivery systems.

Cefixime is a broad-spectrum, third-generation cephalosporin antibiotic derived semisynthetically from the marine fungus Cephalosporium acremonium with antibacterial activity. Cefixime is highly stable in the presence of beta-lactamase enzymes. As a result, many organisms resistant to penicillins and some cephalosporins due to the presence of beta-lactamases, may be susceptible to cefixime. The antibacterial effect of cefixime results from inhibition of mucopeptide synthesis in the bacterial cell wall. Cefixime can be administered by different routes: oral and intravenous. The convenience of oral administration is attractive. However, orally delivered cefixime is rapidly cleared by first-pass hepatic metabolism $(50 \%)$ and this result in poor bioavailability. Consequently, evidence has indicated that orally administered cefixime has lesser efficacy for the treatment of urinary tract infections.

By incorporation of cefixime in phytosme, the drug delivery system was successfully developed that showed sustained release and could be potentially useful to overcome poor bioavailability problems associated with cefixime.

Drug-phospholipid complexes improve the bioavailability of drugs which have either very low lipid solubility or very poor water solubility. Therefore, drug can be complexed for improving biopharmaceutical properties. In addition to improving the drug absorption, drugphospholipid complexes also have the following advantages: 1) increasing the stability of drugs, 2) prolonging the duration of action of drugs.

Before phytosome development, preformulation studies were carried out to characterize the chemical and physical properties of drug substance. The FT-IR spectrum of drug samples was found to be in concordant with the reference chemical groups present in the structure of the cefixime. The UV spectrum of cefixime exhibited a broad band at $288 \mathrm{~nm}$. The melting point was determined by capillary method which complies with the melting point given in reference. The solubility results showed that cefixime highly soluble in methanol. The solubility profile of drug in different solvents shows that drug is hydrophilic in nature which is further confirmed by the partition coefficient study.

The standard curves of cefixime were prepared methanol: water and the absorbance data obtained subjected to linear regression. The correlation coefficients were found to be 0.998 for cefixime which is closed to one indicated for good linearity.

The preformulation study (FT-IR spectrum, UV spectrum and melting point) results suggested that cefixime was pure and good in quality and the estimation procedure was found to be quite reliable, accurate and suitable for formulation development.

Phytosomal formulation of cefixime was prepared by using the reflux technique method.

For optimization of Phytosome, different formulations (F1 to F7) were prepared using the various quantities of lipid. Formulation (F4) with maximum n-octanol solubility, entrapment efficiency and optimum size considered as optimized formulation.

The shape and size of the optimized F4 formulation was confirmed through microscope and particle size and found that most of the particles were well identified.

Optimized formulation in vitro drug release was studied in phosphate buffer saline (PBS) $\mathrm{pH} 6.8$ using dialysis method. To know precisely, the rate and mechanism of 
drug release, the in vitro data was fitted to zero order, first order, Higuchi and Korsmeyer-Peppas model. The results showed that the drug release of F4 formulation followed Higuchi order which describes that the cefixime follows a sustain mechanism for release from phytosome.

\section{REFERENCE}

1. Mehta A, Jain N, Grobler A, Bharti V. Role of Novel Drug Delivery Systems in Bioavailability Enhancement: At A Glance, Int. J. Drug Del. Tech., 2016; 6(1);7-26

2. Patel RR, Patel JK. Novel Technologies of Oral Controlled Release Drug Delivery System, Dep. Pharm. Tech., Systematic Reviews in Pharmacy, 2010; 1(2):128-132

3. Gold J, Laxer D, Rochon P (2000) Herbal remedies; a critical perspective. Ann R Coll Physician Surg Can 33: 497-498.

4. Gupta A, Ashawal MS, Saraf S, Phytosome: a novel approach towards functional cosmetics. J Plant Science. 2007; 644-649.

5. Kumari P, Singh N, Cheriyan P, Neelam, Phytosome: a noval approach for phytomedicine. International Journal of Institutional Pharmacy and Life Sciences.2011; 1:89-100.

6. More MS, Shende MA, Kolhe DB, JNM. Herbosomes: herbophospholipid complex an approach for absorption enhancement, Int. J. Biol. Pharm. Res., 2013; 4(9):634-639.

7. Kuamwat RS, Mruthunjaya K, G. M. K. Preparation, characterisation and antioxidant activities of gallic-acid phospholipid complex, Int. J. Res. Pharm. Sci., 2012; 2:138-148.

8. Pathak K, Das RJ. Herbal Medicine-A Rational Approach in Health Care System, Int. J. Herb. Med. IJHM1, 201; 1(13):86-89.

9. Tripathy S, Patel DK, Barob L, Naira SK. A review on phytosomes, their characterization, advancement \& potential for transdermal application, J. Drug Del. and Ther., 2013; 3(3):147-152

10. Jing Li, Xulin W, Ting Z, Chunling W, Zhenjun H, Xiang L, Yihui D. A review on phospholipids and their main applications in drug delivery systems, Asian J. Pharm. Sci., 2104; 10(2);81-98.

11. Dhiman A, Nanda A, S. A. Novel Herbal Drug Delivery System (NHDDS) : the need of hour, Int. Conf. Environ. Energy Biotechnol, 2013; 51(26):139-142.

12. Jadhav S. M, Morey P, Karpe MM, Kadam V. Novel vesicular system: An overview, J. Appl. Pharm. Sci., 2012; 2(1); 193-202.
13. Saraf S, Khan J, Alexander A, Ajazuddin \& Saraf S. Recent advances and future prospects of phyto-phospholipid complexation technique for improving pharmacokinetic profile of plant actives, $J$. Control. Release, 2013; 168(1):50-60.

14. Amit P, Tanwar YS, Rakesh S, Poojan P. Phytosome : Phytolipid Drug Delivery System for Improving Bioavailability of Herbal Drug, J. Pharm. Sci. Biosci. Res., 2013:3(2); 51-57.

15. Bombardelli E. Phytosome: new cosmetic delivery system. Boll Chim Farm. 1991; 130(11): 431-438.

16. Sharma S, Sikarwar M. Phytosome: A review, Plant indica. 2005; 1(2): 1-3.

17. Manthena S., Srinivas P. Sadanandam. Phytosome in herbal drug delivery. Journal of natural Pharmaceutils. 2010; 1(1):16.

18. Qunyou Tan, Shan Liu, Xueliang Chen, Mingjun Wu, Hong Wang, Huafeng Yin, Dan He, Huarong Xiong, and Jingqing Zhang. Design and evaluation of a novel evodiamine-phospholipid complex for improved oral bioavailability. AAPS PharmSciTech. 2012; 13(2): 534-547.

19. Bruce A, Alexander J, Julian L, Martin R, Keith R, Peter W. Molecular Biology of the Cell. 4th ed. New York; Garland Sciences: 2002.

20. Constantinides PP, Chaubal MV, Shorr R. Advances in lipid nanodispersions for parenteral drug delivery and targeting. Adv Drug Deliv Rev 2008; 60(6):757-67.

21. Singh A, Saharan VA, Singh M, Bhandari A. Phytosome: Drug delivery system for polyphenolic phytoconstituents. Iranian $\mathbf{J}$ of Pharm Sci. 2011; 7:209-219.

22. Zierenberg O, Grundy SM. Intestinal absorption of polyenephosphatidylcholine in man, J Lipid Res. 1982; 23:11361142.

23. Chaurio RA, Janko C, Munoz LE, Frey B, Herrmann M, Gaipl US Phospholipids: Key Players in Apoptosis and Immune Regulation. Molecules 2009; 14(12):4892-914.

24. Sarika D, Khar RK, Chakraborthy GS, Saurabh M. Phytosomes:A Brief overview. J Pharm Res 2016; 15(2):56-62.

25. Suslick KS. Kirk-Othmer encyclopedia of chemical technology. New York: Wiley\&Sons; 1998.

26. Das MK, Kalita B. Design and Evaluation of Phyto-Phospholipid Complexes (Phytosomes) of Rutin for Transdermal Application. J Appl Pharm Sci 2014; 4(10):051-7. 